\title{
Studies on Interaction between Inorganic Material and Polymer by Inverse Gas Chromatography
}

\author{
Yoshimasa MuraKamI \\ Faculty of Liberal Arts, Shinshu University, \\ 3-1-1 Asahi, Matsumoto, Nagano 390, Japan
}

(Received October 18, 1993)

\begin{abstract}
Inverse gas chromatography of columns prepared with a polymer blend of poly(ethylene oxide) (PEO) and poly(methyl methacrylate) (PMMA) in the presence of a pulverized porous inorganic material of silica gel has been studied. Information on interaction between PEO/PMMA blends and silica gel was obtained from the change in the retention diagrams. Silica gel incorporated both PEO and PMMA into its pores. The ability of incorporation of PEO into the pores of silica gel was superior to that of PMMA.
\end{abstract}

KEY WORDS Inverse Gas Chromatography/Polymer Blend / Poly(ethylene oxide) / Poly(methyl methacrylate) / Silica Gel / Compatibility / Transition Behavior / Thermal Treatment /

In recent years many studies on inorganicspolymer interaction have been made by various methods to develop new composite materials. ${ }^{1-5}$ Inverse gas chromatography (IGC) is a useful technique to determine physical properties of a polymer, such as glass transition temperature $\left(T_{\mathrm{g}}\right)$ or melting temperature $\left(T_{\mathrm{m}}\right){ }^{6}$ By using IGC, we have investigated the morphology of hydrophilic-hydrophobic polymer systems such as polymer blends of poly(ethylene oxide) (PEO) and polystyrene (PS), ${ }^{7}$ of poly(acrylic acid) and $\mathrm{PS},{ }^{8}$ of PEO and poly(methyl methacrylate) (PMMA), ${ }^{9}$ and triblock copolymers of PEO and PMMA ${ }^{10}$ which were prepared anionically by us. ${ }^{11-13}$

In the study of PEO/PS blend, we clarified that even a slight change in surface structure of the polymer blend can be detected by IGC. ${ }^{7}$ In a previous paper, we investigated the dispersion states of porous inorganic materials in PEO/PS blend by IGC. ${ }^{14}$ Since PEO and PS are incompatible, phase separation occurred and the surface of the PS domain always protruded above the PEO domain regardless of the composition. ${ }^{7}$ Porous inor- ganic materials such as silica gel selectively incorporated PEO into their pores and the incorporation ability increased with increasing surace area of them. ${ }^{14}$

The morphological study of PEO/PMMA blends is of great interest, since they consist of hydrophilic and hydrophobic polymers. Many studies on PEO/PMMA blends by various techniques have been reported..$^{4,15-25}$ In the previous study, we investigated the transition phenomena of PEO/PMMA blends of various compositions by IGC and clarified that surface feature of the blend varies sensitively with the composition. ${ }^{9}$

In this study, IGC measurements of columns prepared with PEO/PMMA blend and silica gel were carried out. This paper describes the effect of addition of silica gel to PEO/PMMA blend on the compatibility and the results are compared with those of $\mathrm{PEO} / \mathrm{PS}$ blend reported previously. ${ }^{14}$ 


\section{EXPERIMENTAL}

\section{Materials}

Nakarai Chemical's PEO $\# 6000\left(M_{n}=8500\right)$ was used as received. PMMA $\left(M_{n}=46800\right)$ was prepared by radical polymerization of methyl methacrylate in benzene at $60^{\circ} \mathrm{C}$ initiated with AIBN. Silica gel (Merck's silica gel 60, BET surface area $537 \mathrm{~m}^{2} \mathrm{~g}^{-1}$ ) was pulverized by dry-grinding in agate mortar for $1 \mathrm{~h}$. Chromosorb P AW-DMCS 60-80 mesh (JohnsManville Co., BET surface area $3 \mathrm{~m}^{2} \mathrm{~g}^{-1}$ ), which is a good solid support for IGC measurements, ${ }^{26}$ was used as a support for the polymer.

\section{Columns}

The columns prepared in this series of experiments are summarized in Table I. A certain amount of pulverized silica gel was dispersed in a benzene solution $(2.5 \mathrm{w} / \mathrm{v} \%)$ of PEO/PMMA blend by stirring sufficiently, and to this a prescribed amount of Chromosorb was added. The benzene was allowed to evaporate at ambient temperature by gentle and continuous stirring of the solution followed by drying at $45^{\circ} \mathrm{C}$ under slightly reduced pressure. A weighed amount of Chromosorb

Table I. Column specifications

\begin{tabular}{|c|c|c|c|c|}
\hline \multirow{3}{*}{$\begin{array}{c}\text { Column } \\
\text { No. }\end{array}$} & \multicolumn{3}{|c|}{ Polymer } & \multirow{3}{*}{$\begin{array}{c}\begin{array}{c}\text { Silica gel } \\
\text { loading }\end{array} \\
\text { wt } \%\end{array}$} \\
\hline & \multirow{2}{*}{ Sort } & PEO content & Loading $^{\mathrm{a}}$ & \\
\hline & & wt $\%$ & $w t \%$ & \\
\hline 1 & PEO & 100 & 9.8 & 0 \\
\hline 2 & PMMA & 0 & 9.7 & 0 \\
\hline 3 & Blend & 5 & 9.7 & 0 \\
\hline 4 & Blend & 50 & 9.7 & 0 \\
\hline 5 & Blend & 5 & 10.0 & 0.5 \\
\hline 6 & Blend & 5 & 9.7 & 3.8 \\
\hline 7 & Blend & 50 & 9.9 & 0.5 \\
\hline 8 & Blend & 50 & 9.6 & 3.8 \\
\hline
\end{tabular}

a Polymer (g)/[Polymer (g) + Chromosorb (g) + Silica gel $(\mathrm{g})] \times 100$.

b Silica gel $(\mathrm{g}) /[$ Polymer $(\mathrm{g})+$ Chromosorb $(\mathrm{g})+$ Silica gel $(\mathrm{g})] \times 100$. prepared in this manner was tightly packed into a $1.5 \mathrm{~m} \times 3 \mathrm{~mm}$ internal diameter stainlesssteel column. The column was dried for $5 \mathrm{~h}$ at $45^{\circ} \mathrm{C}$ under a constant stream of helium.

\section{Measurements}

Gas chromatograms were recorded on a Shimadzu GC-8A equipped with a thermal conductivity detector, with helium as a carrier gas, n-nonane as a solute, and air as a noninteracting marker. The method of IGC measurement has been decribed in previous papers. $^{7,8,10}$ The gas chromatographic measurement was carried out by increasing the column temperature $T(\mathrm{~K})$. The specific retention volume $V_{\mathrm{g}}\left(\mathrm{mlg}^{-1}\right)$ was calculated from the equation $V_{\mathrm{g}}=V_{\mathrm{N}} / w . V_{\mathrm{N}}(\mathrm{ml})$ is the net retention volume of the solute from the air peak and $w(\mathrm{~g})$ is the loaded polymer weight in the column. The retention diagram (RD) was obtained by plotting $\log V_{\mathrm{g}}$ vs. $10^{3} / T$. Several days after the first measurement on a freshly packed column, the second measurement was carried out to investigate the influence of the thermal treatment on the surface feature of the polymer. The BET surface area of silica gel was measured on a Shibata SA-1000 by one-point $\mathrm{N}_{2}$-adsorption method at liquid nitrogen temperature.

\section{RESULTS AND DISCUSSION}

Figure 1 shows the retention diagrams (RDs) of the first measurement (RDs-1st) of the columns No. 1 and No. 2 together with the RDs of the second measurement (RDs-2nd). In a Z-shaped curve, the temperature of the first deviation from linearity corresponds to the transition temperature of the polymer. ${ }^{6}$ As can be seen from Figure 1, the $T_{\mathrm{m}}$ of PEO and the $T_{\mathrm{g}}$ of PMMA were about 62 and $115^{\circ} \mathrm{C}$, respectively. It should be noted that the value of $\log V_{\mathrm{g}}$ in the RD of PEO at a certain temperature is fairly larger than that in the RD of PMMA. The RD-2nd reflects the thermallytreated phase structure of the polymer. The 


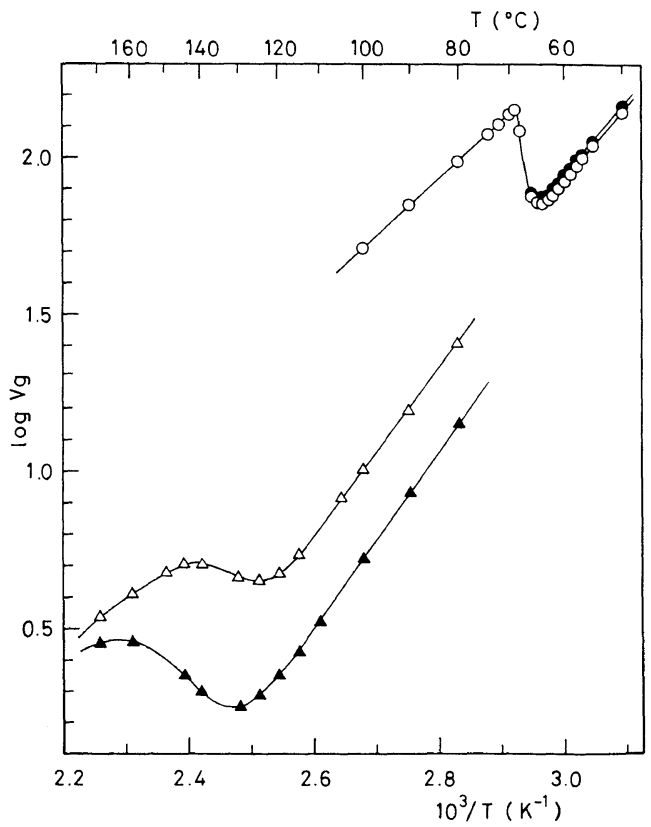

Figure 1. Retention diagrams of PEO and PMMA: $(O)$ column No. 1 (PEO, first measurement); (O) No. 1 (second); $(\triangle)$ No. 2 (PMMA, first); ( $\Delta$ ) No. 2 (second).

retention mechanism were reported previously. ${ }^{6,8,9}$ In brief, the result that the RD-2nd is not so different from the RD-1st is a characteristic of PEO. ${ }^{9}$ On the other hand, the result that the value of $\log V_{\mathrm{g}}$ in $\mathrm{RD}-2 \mathrm{nd}$ is smaller than that in the RD-1st (downward shift of RD) is a characteristic of PMMA. ${ }^{9}$

The RDs of the third measurements were the same as the respective RDs-2nd. Therefore, it is not necessary to take into account the result of the third measurements to discuss the effect of thermal treatment on phase structure of the polymer. ${ }^{26}$ Thermal hysteresis in RDs is not due to the characteristic of silica gel but to that of polymer. ${ }^{7-9,14,26}$

In Figure 2 are shown the RD-1st and RD2nd of column No. 3 ( $5 \mathrm{wt} \%$ PEO, without additive) and the RD-1st of column No. 4 ( $50 \mathrm{wt} \%$ PEO, without additive). In the RD-1st of $5 \mathrm{wt} \% \mathrm{PEO}$, the Z-shaped curves at 62 and $115^{\circ} \mathrm{C}$ were not observed. Instead, a Z-shaped curve at $97^{\circ} \mathrm{C}$ and a very slight bending of the slope at $58^{\circ} \mathrm{C}$ were observed. The former is

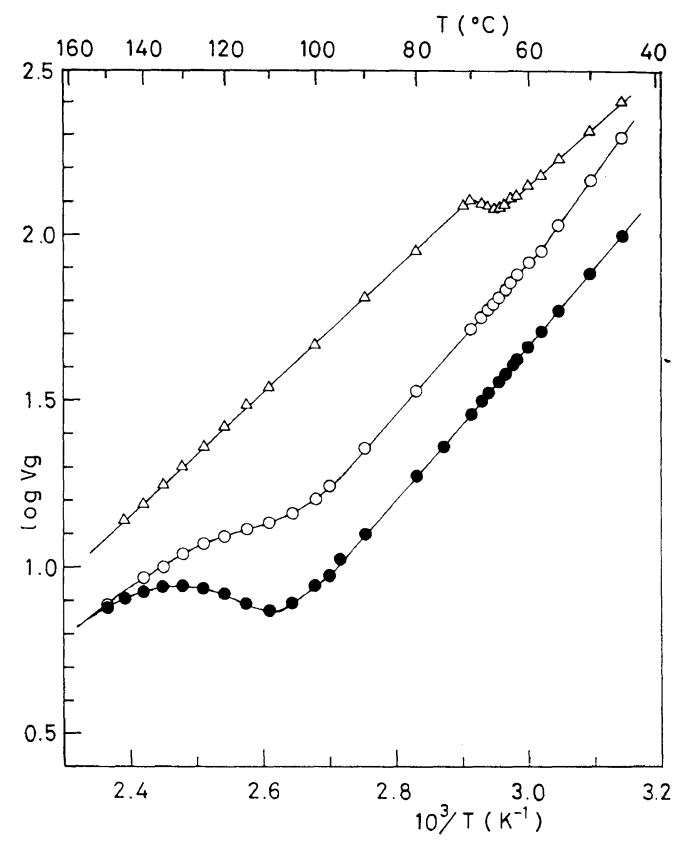

Figure 2. Retention diagrams of PEO/PMMA blends without silica gel: $(O)$ column No. $3(5 \mathrm{wt} \%$ PEO, first measurement); (๑) No. 3 (second); $(\triangle)$ No. 4 (50 wt \% PEO, first).

mainly attributable to the glass transition of PMMA and the latter to the melt transition of PEO. In the RD-2nd of $5 \mathrm{wt} \%$ PEO, the fundamental pattern of the RD was the same as the RD-1st, while downward shift of RD was observed. In a PEO/PMMA blend of $5 \mathrm{wt} \%$ PEO, therefore, both components are miscible each other and the polymer system is almost homogeneous. However, the physical property is mainly determined by the PMMA component. This interpretation is consistent with the report by Liberman et al. ${ }^{27}$ The fundamental transition behavior of the blend does not change by thermal treatment in this composition.

In the RD-1st of $50 \mathrm{wt} \%$ PEO, a Z-shaped curve was clearly observed at $64^{\circ} \mathrm{C}$ and a bending of the slope was hardly observable at around $110^{\circ} \mathrm{C}$. The shape of RD-2nd was completely the same as that of RD-1st. In a PEO/PMMA blend of $50 \mathrm{wt} \%$ PEO, therefore, PEO domains exist in the homogeneous 


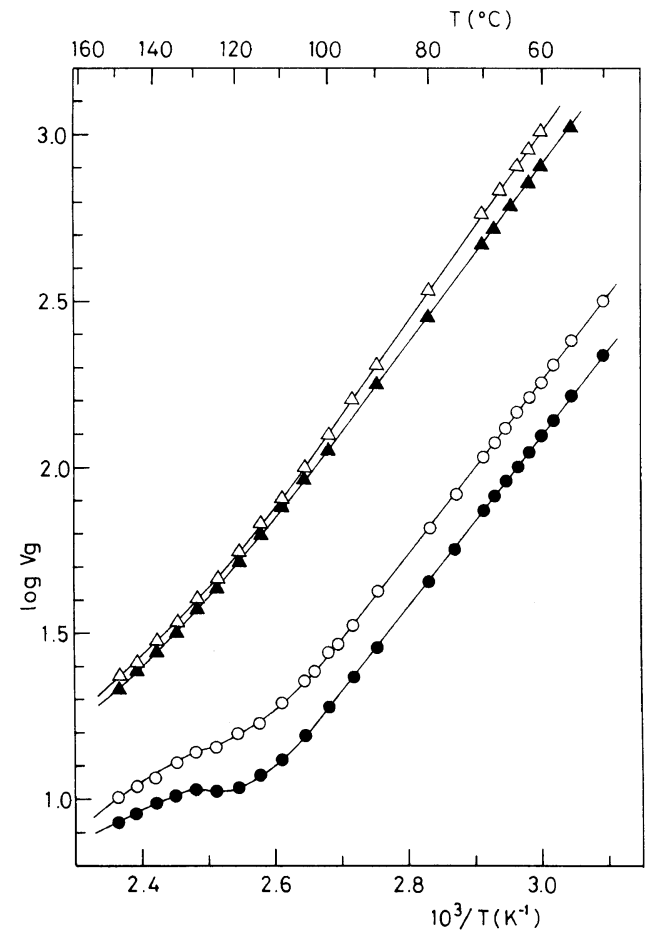

Figure 3. Retention diagrams of PEO/PMMA blends with silica gel: $(\bigcirc)$ column No. 5 (5 wt $\%$ PEO, $0.5 \mathrm{wt} \%$ silica gel, first measurement); $(\bigcirc)$ No. 5 (second); $(\triangle)$ No.

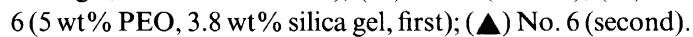

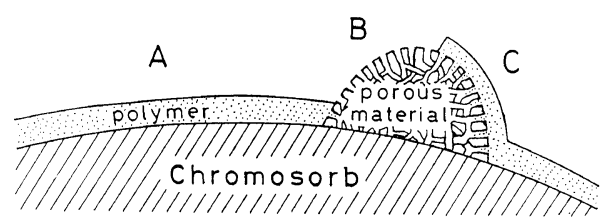

Figure 4. A model for adsorption sites for $n$-nonane.

polymer matrix. Although the PEO domains may partially melt, the fundamental feature of the blend does not change by thermal treatment. In PEO/PS blends, PEO and PS are incompatible and phase separation occurred above $20 \mathrm{wt} \%$ PEO. $^{7}$

Figure 3 shows the RDs of columns No. 5 and No. 6 in which PEO/PMMA blend ( $5 \mathrm{wt} \%$ PEO) and silica gel were loaded on the Chromosorb. To interpret the results a model for adsorption sites for solute on Chromosorb was proposed in a previous paper ${ }^{14}$ and is shown in Figure 4. Three sites were considered in the retention mechanism: the surface of polymer which covers the Chromosorb surface (site A); the uncovered surface of porous inorganic material of silica gel (site B); the polymer-covered part of silica gel where all the pores are filled with polymer (site C). As the surface area of polymer at site $\mathrm{A}$ is much larger than that at site $\mathrm{C}$, the adsorption-desorption of the solute (n-nonane) at site A mainly governs the retention mechanism.

In the RD-1st of $0.5 \mathrm{wt} \%$ silica gel in Figure 3 , the bending of the slope at $58^{\circ} \mathrm{C}$ disappeared, which indicates that PEO was incorporated into the pores of silica gel (increase in the amount of site C) and the amount of PEO at site A decreased. Further, the Z-shaped curve shifted from $97^{\circ} \mathrm{C}$ to $\mathrm{ca} .105^{\circ} \mathrm{C}$. The $T_{\mathrm{g}}$ which is mainly attributed to the glass transition of PMMA component in the blend approached the $T_{\mathrm{g}}$ of homo PMMA $\left(115^{\circ} \mathrm{C}\right)$, since plasticizing effect of PEO decreased according to the decrease in the amount of PEO at site A. In the RD-1st of $3.8 \mathrm{wt} \%$ silica gel in Figure 3 , the Z-shaped curve disappeared and a bending of the slope was observed at around $110^{\circ} \mathrm{C}$. If silica gel incorporates only PEO into its pores, the composition of PMMA component increases at site $\mathrm{A}$ and the $\mathrm{Z}$-shaped curve should be clearly observed at around $115^{\circ} \mathrm{C}$. Therefore, silica gel incorporates not only PEO but PMMA into its pores. In the PEO/PS blend, silica gel selectively incorporated PEO into the pores. ${ }^{14}$

Downward shifts of RD were observed in the RDs-2nd, which indicates that the transition behavior of the blend is mainly governed by PMMA even at $3.8 \mathrm{wt} \%$ silica gel.

Figure 5 depicts the RD-1st of column No. $7(50 \mathrm{wt} \%$ PEO, $0.5 \mathrm{wt} \%$ silica gel) and the RD-1st, RD-2nd of column No. $8(50 \mathrm{wt} \%$ PEO, $3.8 \mathrm{wt} \%$ silica gel). As previously reported, in $50 \mathrm{wt} \%$ PEO without silica gel, PEO domains protrude from the homogeneous polymer matrix in which PEO and PMMA are miscible, that is, PEO domain exists as island 


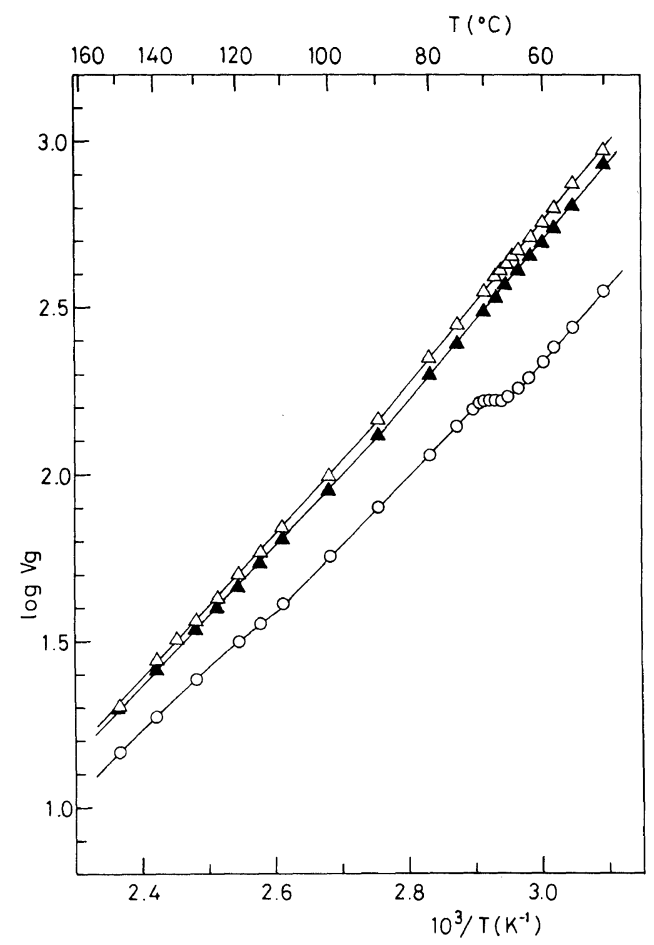

Figure 5. Retention diagrams of PEO/PMMA blends with silica gel: $(\bigcirc)$ column No. 7 (50 wt $\%$ PEO, $0.5 \mathrm{wt} \%$ silica gel, first measurement); $(\triangle)$ No. 8 (50 wt \% PEO, $3.8 \mathrm{wt} \%$ silica gel, first); (A) No. 8 (second).

phase. ${ }^{9}$ The RD-2nd of column No. 7 was almost the same as the RD-1st. In the RD of $0.5 \mathrm{wt} \%$ silica gel, a Z-shaped curve mainly due to PEO component and a slight change of the slope mainly due to PMMA component were observed at $66^{\circ} \mathrm{C}$ and $110^{\circ} \mathrm{C}$, respectively. These results indicate that, in $0.5 \mathrm{wt} \%$ silica gel, silica gel does not incorporate all of the island phase of PEO at site $\mathrm{A}$ into its pores. The result that in $0.5 \mathrm{wt} \%$ silica gel the RD-2nd was almost the same as the RD-1st further supports the interpretation that characteristic of PEO governs the feature of the blend. Further, although characteristic of PEO governs the feature of the blend, characteristic of PMMA slightly appears. If ability of incorporation of PEO is identical with that of PMMA, the composition of the blend is constant ( $50 \mathrm{wt} \%$ PEO) and the bending of the slope at around $110^{\circ} \mathrm{C}$ in RD is expected not to be observed. Therefore, appearance of the bending at around $110^{\circ} \mathrm{C}$ indicates that ability of incorporation of PEO into the pores of silica gel is superior to that of PMMA.

In the RDs of $3.8 \mathrm{wt} \%$ silica gel, the Zshaped curves at around $62^{\circ} \mathrm{C}$ disappeared and the bendings of the slope appeared very slightly at around $90^{\circ} \mathrm{C}$. Disappearance of the $\mathrm{Z}$-shaped curves indicates that the island phase of PEO at site A was completely incorporated into the pores of silica gel. In $3.8 \mathrm{wt} \%$ silica gel, appearance of the bending of the slope and the downward shift of the RD-2nd show the appearance of characteristic of PMMA in the blend of $50 \mathrm{wt} \%$ PEO. As compared Figure 3 with Figure 5, the RD of $50 \mathrm{wt} \%$ PEO was observed at upper side than that of $5 \mathrm{wt} \%$ PEO in $0.5 \mathrm{wt} \%$ silica gel. This result further supports the interpretation described above.

The increase in the amount of addition of silica gel will result in the increase in the surface area of site B. In such a case, adsorption-desorption of $n$-nonane at site B should affect the retention mechanism because of strong adsorption on silica gel. As can be seen from Figures 3 and 5 , the increase in the amount of silica gel resulted in the upward shift of RD which means occurrence of stronger adsorption of $n$-nonane at site $\mathrm{B}$. The same tendency was observed in the case of PEO/PS blends. ${ }^{14}$

Quantitative analysis regarding incorporation of PEO into the pore of silica gel in PEO/PS blends was briefly made in the previous paper. ${ }^{14}$ Quantitative interpretation in PEO/PMMA blends is considered to be fundamentally the same as the previous interpretation. More detailed quantiative analyses are in progress.

\section{CONCLUSIONS}

In PEO/PS blends, a porous inorganic material of silica gel selectively incorporated PEO into the pores. ${ }^{14}$ On the other hand, in PEO/PMMA blends, silica gel incorporated 
not only PEO but PMMA into its pores. However, the ability of incorporation of PEO into the pores of silica gel was superior to that of PMMA.

IGC measurments of multicomponent polymer systems such as polymer blends offer valuable information on transition phenomena, compatibility, thermal treatment and so on. Information on these delicate features was hardly obtainable by the differential scanning calorimetry (DSC) in our laboratory. Especially, the change by thermal treatment could not be detected by our DSC measurements. Thus, IGC is a simple, sensitive and useful technique and will be widely applicable to studies on many other multicomponent polymer systems.

\section{REFERENCES}

1. A. M. Gessler, Rubber Chem. Technol., 37, 1034 (1964).

2. N. Schamp and J. Huylebroeck, J. Polym. Sci., Polym. Symp. Ed., 42, 553 (1973).

3. D. S. Drumheller, J. Appl. Phys., 53, 957 (1982).

4. Z. Florianczyk, K. Such, W. Wieczorek, and M. Wasiucionek, Polymer, 32, 3422 (1991).

5. T. Saegusa, J. Macromol. Sci.-Chem., A28 (9), 817 (1991).

6. J. M.-Braun and J. E. Guillet, Adv. Polym. Sci., 21, 107 (1976).

7. T. Suzuki, Y. Murakami, T. Inui, and Y. Takegami, Polym. J., 13, 1027 (1981).

8. Y. Murakami, T. Inui, and Y. Takegami, Polym. J., 15, 415 (1983).
9. Y. Murakami, Polym. J., 20, 549 (1988).

10. T. Inui, Y. Murakami, T. Suzuki, O. Yamada, and Y. Takegami, Macromolecules, 17, 195 (1984).

11. T. Suzuki, Y. Murakami, Y. Tsuji, and Y. Takegami, J. Polym. Sci., Polym. Lett. Ed., 14, 675 (1976).

12. T. Suzuki, Y. Murakami, and Y. Takegami, Polym. J., 12, 183 (1980).

13. T. Suzuki, O. Yamada, Y. Murakami, Y. Takegami, and Y. Watanabe, Macromolecules, 15, 223 (1982).

14. Y. Murakami, T. Inui, and Y. Takegami, Polymer, 24, 1596 (1983).

15. E. Martuscelli, M. Canetti, L. Vicini, and A. Seves, Polymer, 23, 331 (1982).

16. M. M. Cortazar, M. E. Calahorra, and G. M. Guzman, Eur. Polym. J., 18, 165 (1982).

17. J. M. Elorza, M. J. Fdz-Berridi, J. J. Iruin, and G. M. Guzman, Polym. Eng. Sci., 24, 287 (1984).

18. M. E. Calahorra, M. M. Cortazar, and G. M. Guzman, J. Polym. Sci., Polym. Lett. Ed., 23, 257 (1985).

19. C. Silvestre, S. Cimmino, E. Martuscelli, F. E. Karasz, and W. J. Macknight, Polymer, 28, 1190 (1987).

20. H. Ito, T. P. Russell, and G. D. Wignall, Macromolecules, 20, 2213 (1987).

21. T. P. Russell, H. Ito, and G. D. Wignall, Macromolecules, 21, 1703 (1988).

22. S. Shimada, K. Kashima, Y. Hori, and H. Kashiwabara, Kobunshi Ronbunshu, 47, 379 (1990).

23. M. Takahashi, N. Harasawa, and H. Yoshida, Kobunshi Rounbunshu, 47, 455 (1990).

24. C. Nakafuku and N. Toyonaga, Polymer, 33, 2370 (1992).

25. J. A. Zawada, C. M. Wlitalo, G. G. Fuller, R. H. Colby, and T. E. Long, Macromolecules, 25, 2896 (1992).

26. T. Inui, Y. Murakami, T. Suzuki, and Y. Takegami, Polym. J., 14, 261 (1982).

27. S. A. Liberman, A. S. Gomes, and E. M. Macchi, $J$. Polym. Sci., Polym. Chem. Ed., 22, 2809 (1984). 